\title{
Review on Accidents Related to Human Factors at Construction Site
}

\author{
KAMAL, I. S. M. ${ }^{1, a}$, AHMAD, I. N. ${ }^{1, b}$, MA'AROF, M. I. N. ${ }^{1, c}$ \\ ${ }^{1}$ Faculty of Mechanical Engineering, \\ UniversitiTeknologi Mara, 40450 Shah Alam, Selangor, Malaysia \\ aintanmk89@gmail.com, biahmad886@gmail.com, 'cmuhammad.izzat87@gmail.com
}

Keywords: construction industry, human factors, safety performance, hazards, accidents, training, work physiology, working selection.

\begin{abstract}
The construction sector is among the most hazardous industry due to the working environment which exposes workers to high risk of accidents. Statistics by the Malaysian Ministry of Human Resource had shown that the number of mortality and disability cases involving construction workers were the highest among the other sectors. Most of the cases were caused by unidentified hazards around the construction sites. The literature had documented that environmental factors were responsible for most of the cases. This paper aims to highlight on the causation factors of accidents and injuries at the construction sites based on the human factor. Selected journals and research papers related with accidents at construction sites were reviewed and human error was found to be the main causation factor of accidents at construction sites. This study urges for more in depth study on the actions or interventions that could be taken to minimize the occurrence of human error in the construction site, thus, minimizing the occurrence of accidents, injuries and even mortality.
\end{abstract}

\section{Introduction}

In most countries, construction is the largest industry both in economic output and in the number of people employed. For instance, the number of construction projects increased annually as witnessed by the author within the Klang Valley district of the state of Selangor Darul Ehsan in Malaysia. Although the statistic reported by the Ministry of Human Resource of Malaysia [1] have shown a decrement of mortality cases to 48 victims as of October 2012 from 95 victims in 2007, the accident involving permanent and non-permanent disability have shown erratic patterns of increment and decrement for the last five years. Nevertheless, as of 2012, for both accidents involving permanent and non-permanent disability, it was recorded as all-time high since the year 2007.

Table 1. Number of accidents from 2007 until 2012.

(Source: Ministry of Human Resource, Malaysia [1]).

\begin{tabular}{|c|c|c|c|}
\hline Year & $\begin{array}{c}\text { Non-permanent } \\
\text { disability }\end{array}$ & $\begin{array}{c}\text { Permanent } \\
\text { disability }\end{array}$ & Fatality \\
\hline 2007 & 76 & 10 & 95 \\
\hline 2008 & 55 & 2 & 72 \\
\hline 2009 & 38 & 6 & 71 \\
\hline 2010 & 50 & 4 & 66 \\
\hline 2011 & 43 & 5 & 51 \\
\hline 2012 & 85 & 12 & 48 \\
\hline
\end{tabular}

The construction industry is high physical demanding as construction activities performed at outdoor under conditions not conductive for safety and health. Workers have to experience constant changes in the nature of work, the location of work and work with new workers [2]. The researchers found that factors involved in accidents include human behaviour, different construction sites, the difficulties of work, lack of safety culture, unsafe used of machinery and equipment, and 
noncompliance with various sets of procedures. But from the preliminary study, it shows that accidents occurred because of human factors such as worker's behaviour and safety culture among the workers. Therefore, it is necessary to consider these risk factors and manage them accordingly to minimize accidents and injuries at construction site.

Considering the importance of the construction sector and the economic resources generated from the industry, it is surprising that there have been minimal research on the human aspect of construction work. Many previous studies were focused on environmental factors that could lead to accidents rather than investigation on the human perspective of the situation such as the attitudes among the employees with regards to safety [3]. With respect to those findings, this study believes that the changes in the environmental setting may decrease the statistics on accidents and injuries, though it could only be temporary. This study suggested that these changes (the environmental aspects) would be futile if the employees perform their work under negligence and disregard towards safety and accidents prevention. Thus, there is the need to study on the human aspect of this situation, for this study truly believes that this is actually the root to the whole crisis.

Due to the minimal amount of studies on human factor with respect to construction site, it is difficult to estimate the magnitude of most human factors related issues. In addition, it is also critical to identify the safety performance at any construction sites by first investigating on the safety behaviour and safety management of the work. Moreover, the information on work physiology is also needed in order to control other factors such as capability, familiarity with the task, gender, and age. Human factors engineering issues and countermeasures on shift work, selection and training have been found in some studies [4] which could provide necessary information on understanding the human factor aspect within the construction sector.

Furthermore, most of accidents investigation was limited and less of human error analysis [5]. There are two issues must be considered in investigation of the causation factors, (1) causal factors of accidents or failures of equipment and (2) contribution factors to human errors, which include a probability of risk to each worker. Human performance in any situation will be influenced by what individuals expect to happen, what has happened in same situation in past, and their assessment of the consequences [6]. Emotional factors such as fear and stress, together with workload, fatigue, and time pressure can also be important influences on human performance and decision making [7]. Therefore, this paper aims to highlight the causation factors of the accidents which occur in the construction site that are related to human factors.

\section{Construction Hazards}

Construction hazards are defined as environmental factors that can cause injury such as noise, chemical debris, scaffold, excavation, roof work, working from ladders and the like [8]. There are two major categories of hazards:

1. The risk of physical injury or physical injury hazards - Hazards that are normally associated with process like scaffolds, ladder, roof work, plant and machinery, excavation, and others [9].

2. The risk of ill health or health hazards - Health hazards in construction site may be grouped in chemical, physical, and biological hazards [10].

This study suggested that the first step on minimizing the cases of accidents and injuries at the construction sites is by successful identification of the types of construction hazardous. The Ministry of Human Resource of Malaysia reported that the most common type of accidents was workers falling from elevated heights and materials falling on the workers [1]. Construction sites commonly require the workers to perform their tasks at elevated heights with the use of scaffolds, platforms and ladders on a daily basis. The events of these elevation platforms collapsing (perhaps due to improper setup or poor material selection) are among the possible reasons for the accidents. Therefore, study of hazards at construction site can become a guideline for the contractors and organisations to prevent accidents by analyzing the condition of materials and machinery used.

Nevertheless, as found by this study, a number of previous studies $[8,9,10]$ did not focus on the ergonomic hazards of the construction work. The term 'ergonomic hazard' is defined by this study 
as the hazards that are not visible to the naked eye. Ergonomic hazard are hazards that occur within the body system of the human operator such as the physiological discomforts and traumatic injuries to the joints and muscles which eventually lead to musculoskeletal disorders (MSDs) [11]. This study emphasizes that the workers cannot perform their tasks effectively under the conditions of physiological stress and strain. Thus, it was classified under human error which by human action that exceeds some limit of acceptability for a process which human was the main component.

Table 2. Types of ergonomic hazards.

(Modified from source: Department of Safety and Health (DOSH)[11])

\begin{tabular}{|c|c|}
\hline Types of Hazards & Descriptions \\
\hline 1. Manual material handling & $\begin{array}{l}\text { Lifting, lowering, carrying, holding } \\
\text { without using any equipment or tools }\end{array}$ \\
\hline 2. Repetitive works & $\begin{array}{l}\text { Repeating same movements over and over } \\
\text { can cause muscle fatigue }\end{array}$ \\
\hline 3. Awkward postures & $\begin{array}{l}\text { Improper postures such as bending and } \\
\text { twisting are assumed }\end{array}$ \\
\hline $\begin{array}{l}\text { 4. Excessive force or overexertion while } \\
\text { performing tasks }\end{array}$ & $\begin{array}{l}\text { Exertion of maximum force can cause } \\
\text { stress in the muscles and tendons }\end{array}$ \\
\hline $\begin{array}{l}\text { 5. The use and selection of incorrect tools } \\
\text { for the tasks }\end{array}$ & Unsuitable tool used can cause fault \\
\hline $\begin{array}{l}\text { 6. The use and selection of improperly } \\
\text { maintained tools for the tasks }\end{array}$ & $\begin{array}{l}\text { Can cause defective and unprepared } \\
\text { condition }\end{array}$ \\
\hline
\end{tabular}

\section{Safety Culture}

Accident theory on human factors shows that there is a chain of events which are caused by human faults. In this theory, there are general factors causing human faults such as overload, irrelevant response, and irrelevant activities. Culture involves learned and shared behaviours, norms, values, and material objects [12]. Overall safety culture can be described as a set of beliefs, norms attitudes and social technical practices that are concerned with minimizing the exposure of individuals, within and beyond an organization, to conditions considered dangerous or injurious [13]. The researchers found almost the same theory about safety culture among workers in any organization.

The environmental factors consist of site conditions, site tidiness, availability of technical resource, inter or intra-group cooperation, control and supervision of work, effectiveness of longterm planning and pay structure. The psychological factors were acknowledged as care and attention by the individual, skill and experience brought to the job, safety training, and origins of safety norms, perceived responsibilities and feeling of competent autonomy or fatalism. Nevertheless, the psychological factors were noted to be more closely to safety research [12]. This study suggested that the investigation of attitudes towards safe behaviour and its relationship to the management of safety performance is timely, especially when one considers the worldwide trend towards self-regulation of safety management.

$\mathrm{Na}$ Guo [14] proposed a conceptual model by reviewing the literatures on safety climate, safety behaviour, personal issues, safety evaluation and others in order to improve safety performance of construction workers. This study found that the particular conception model found was beneficial to evaluate the safety issues among the workers. However, it seems to be one-sided since the employers or management of the construction project was not evaluated. It was reported that accidents occurring at construction site were mainly caused by environmental factors and psychological factors of the individual workers [15].

The identification of those attitudes and beliefs that mostly linked to the effectiveness of behavioural management programs is important in determining the safety attitudes among the workers [16]. The researchers identified the aspects of company safety management that lead to 
positive attitudes to safety among the workers [13, 14, 15, and 16]. Most of them were heavily focused only on the productivity and may leads to the contribution of human error where the workers were severely lack of motivation and awareness of safety. This study deduced that if techniques such as safety behaviour are to be successful in the construction industry, a positive safety attitude is an essential prerequisite to eliminate accidents at construction site.

\section{Work Physiology}

Work physiology is an aspect of industrial engineering that evaluates metabolic cost, measurement and prevention of work strain, and other ergonomic factors in the design of task and workplaces [17]. Thus, it involves the capacity for physical labour that was found to be different from person to another. Examples of work physiology are the level of physical fitness, nutritional status, age, gender and health. Work capacity decreases gradually throughout life following the peak in the early years [18]. It was noted that older workers can perform task slowly with proper skills, but younger workers will perform their task consistently at a much faster pace [19]. Therefore, physical screening is important to determine the capability in every worker to fit them with the task.

Work-rest scheduling is one of work physiology issues that can be defined as any arrangement of working hours other than the usual to provide more rest hours for the workers to recharging their energy [18]. The duration of bouts and rest pauses should be regulated to account for the worker's age. Tasks that demand high proportion of energy expenditure could only be performed under limited time duration [18]. Improper work-rest scheduling can contribute to accidents which may influence human performance due to lack of task error analysis.

The investigation of the influence of age or aging on job satisfaction of construction workers comprised six items namely personal health, quality of life, personal development, relationship with workmates, relationship with supervisor and satisfaction with occupation [18]. From the observation of this study, there are other issues which were perhaps, overlooked by previous studies. These are the evaluation of task difficulty level, task duration and working posture. These three items are also important to determine the level of job satisfaction between the workers in order to minimize the accidents occurring at construction site during working period.

Individual differences in skill, motivation, body weight, age, gender, involvement of muscle groups while performing the task (related to the technique of performing the task), general health, and degree of physical training, may affect the energy expenditure [19]. In addition, the working posture assumed by the worker to perform the task may produce transient or long-term changes in the musculoskeletal system [19]. Therefore, these three issues are important in reducing the causation factors of accident caused by human error as highlighted in this paper.

\section{Characteristics of worker}

Human factors engineering aims at modifying work procedures and machinery by taking into account the physical and psychological capabilities and limitations of human being. The first scientific efforts to study human performance in the workplace were time and motion studies that were conducted in the early twentieth century [20]. Human engineering methodologies have been applied to many industrial tasks to evaluate accidents cases. Researchers have found the obvious differences among workers with regard to the quality of work done, attitudes, morale, and cooperativeness [21].

The three basic ways for determining worker's characteristics and performance are personnel orientation, selection and training. First way is worker orientation that must be conducted in any type of working position. New workers need to be trained to perform their task safely, to recognize, understand, and avoid potential hazards to themselves and others. Safety manager are responsible for ensuring that both new and experienced workers received the training they need to do their task safely [2]. In addition, contractors (temporary workers, subcontractor workers, visitors, and others) may need specific training to recognize the hazards at construction site. 
The construction industry in Malaysia employed about 9 percent (or 900,000 workers) of the total workforce in the country [1]. However, the sector still depends on foreign labour, especially from Indonesia, Bangladesh, Nepal, Myanmar and Thailand. Approximately 250,000 out of 800,000 construction workers are foreigners as reported by the Malaysian Ministry of Human Resource [1]. Foreign workers are mostly unskilled upon arrival to Malaysia, thus, making considerable impact on the productivity and quality of the construction industry. Furthermore, this study deduce that language barrier due to various ethnicity background in the construction sites would affect the effectiveness of training (either on the task or safety). Consequently, safety on the job could be jeopardised and most probably lead to accidents at the worksite.

Nevertheless, there are also differences between foreign and local worker's capabilities to perform the work task. The differences in anthropometry and physiological conditioning made the migrants perform better in the construction industry. They are familiar with heavy tasks because of their difficulty to gain money for everyday life. Besides, some of the employers take advantage by ignoring the wages rate by selecting migrant workers. Thus if possible, the workers must be protected against undue physical, biological and psychological strain that they experienced while performing the tasks.

Training is important in determining which skills should be developed and the amount of knowledge trainees should acquire. In fact, site manager must also undergo the safety training because they are leaders on site [22]. It shows that management is the main aspect in assessing the need for training. They must analyze such data as independent consultants through interview with workers and informal discussions with supervisors, and by distribute questionnaire set to identify discrepancies between job requirements and individual skills [20]. The data can be beneficial in order to implement a training program. The increased of training duration are associated with lower accident rates.

\section{Conclusion}

Construction industry is the most dangerous sector with the existence of various types of hazards. However, this paper reviewed every subcategory of human factors that could cause accidents at construction site where the use of human skill and energy is much needed. The main human factor is employer attitudes and motivation. The human errors were identified as follow:

1. Unidentified ergonomic hazards.

2. Worst safety behaviour among the management.

3. Improper selection of workers.

4. Insufficient training among the workers.

This study urges for more in-depth study of the human factor aspect involving the construction sector. This study believes that by solving the issue related to human factor, the statistics on the accidents, injuries and mortality cases in the construction could be continuously reduced. Improving human factor analysis can produce not only improvements in safety and health but also gains in quality, productivity and employee job satisfaction.

\section{References}

[1] Accidents Statistic, Department of Safety and Health, Ministry of Human Resource, Kuala Lumpur, Malaysia, 2012.

[2] M. S. Misnan, A. H. Mohammed and W. Y. Mahmood, "Development of Safety Culture in The Construction Industry: The Leadership and Training Roles," Proceeding of the $2^{\text {nd }}$ International Conference on Built Environment in Developing Countries (ICBEDC), Johor, Malaysia, 2008.

[3] F. B. Cambraia, C. T. Formoso and T. A. Saurin, "An analysis of construction safety best practices from cognitive systems engineering perspective," Safety Science, vol. 10, pp. 1-15, Brazil, 2007. 
[4] K. H. E. Kroemer, H. J. Kroemer and Kroemer Elbert, K. E., Engineering Physiology: Base of Human Factor/Ergonomics, $2^{\text {nd }}$ edition, New York: Reinhold, 1990.

[5] N. Haste, "Accidents and Agenda: An examination of the processes that follow from accidents in high potential in several industries and their effectiveness in preventing further accidents," The Royal Academy of Engineering, http://www.raeng.org.uk/news/publications/, July 2007.

[6] J. A. Gambatese, M. Behm, and J. Hinze, "Viability of designing for construction worker safety," Journal of Construction Engineering Management, pp. 1029-1036, 2005.

[7] S. A. Shappell and D. A. Wiegmann, "A human error approach to accident investigation: the taxonomy of unsafe operations," International Journal Aviation Psychological, pp. 269-291, 1997.

[8] A. R. A. Hamid, "Hazards at Construction Sites," Proceeding of the $5^{\text {th }}$ Asia Pacific Structural Engineering and Construction Conference (APSEC), Johor Bahru, Malaysia, 2003.

[9] V. J. Davies and K. Tomasin, "Construction Safety Handbook," London: Thomas Telford, (1990)

[10] R. W. King and R. Hudson, Construction Hazard and Safety Handbook, London, 1985.

[11] Division of Occupational Safety and Health, Washington, 2011.

[12] R. T. Booth, "The role of human factors and safety culture in safety management," Successful Management for Safety, London, 1993.

[13] M. S. Misnan and A. H. Mohammed, "Development of Safety Culture in the Construction Industry: A Conceptual Framework," Proceeding of the $23^{\text {rd }}$ Annual Conference, Belfast, United Kingdom, pp. 45-49, September 3-5, 2007.

[14] N. Guo and S. Yu, "Study on construction worker safety performance improvement model in China," Applied Mechanics and Materials, vols. 174-177, pp. 2729-2733, Hong Kong, (2012)

[15] M. O. Jannadi, "Impact of human relations on the safety of construction workers," International Journal of Project Management, vol. 13, no. 6, pp. 383-386, 1995.

[16] D. Langford, S. Rowlinson and E. Sawacha, "Safety behaviour and safety management: its influence on the attitudes of workers in the UK construction industry," Engineering, Construction and Architectural Management, vol. 7, iss. 2, pp. 133-140, 2000.

[17] N. Chileshe, "The effect of age on the job satisfaction of construction workers," Australia, 2010.

[18] M. Helander, "Human Factors Engineering in Construction Work," Construction, Management and Engineering, pp. 141-182, New York, NY: John Wiley \& Sons. Inc, 1981.

[19] K. H. E. Kroemer, H. J. Kroemer and Kroemer Elbert, Ergonomics: How to Design Ease and Efficienc", $2^{\text {nd }}$ edition, Englewood Cliffs, NJ: Prentice Hall, 2001.

[20] D. W. Christopher, E. G. Sallie , and Yili Liu, Introduction to Human Engineering, $2^{\text {nd }}$ edition, Reinland, 2004.

[21] R. A. Haslam, S. A. Hide, A. G. F.Gibb, D. E. Gyi, T. Pavitt, S. Atkinson and A. R. Duff, "Contributing factors in construction accidents," Applied Ergonomics, vol. 36, pp. 401-415 2005.

[22] B. Hare and I. Cameron, "Site Manager Safety Training," Engineering, Construction and Management, vol. 18, no. 6, pp. 568-578, UK: Glasgow, 2011. 